\title{
Optimal Design and Fabrication of Shoe Lasts for Ankle Foot Orthotics for Patients With Diabetes
}

P.W. Anggoro, Department of Industrial Engineering, Faculty of Industrial Technology, University of Atma Jaya Yogyakarta, Yogyakarta, Indonesia \& Department of Mechanical Engineering, Diponegoro University, Semarang, Indonesia

M. Tauviqirrahman, Department of Mechanical Engineering, Diponegoro University, Semarang, Indonesia

J. Jamari, Department of Mechanical Engineering, Diponegoro University, Semarang, Indonesia

A.P. Bayuseno, Department of Mechanical Engineering, Diponegoro University, Semarang, Indonesia

J. Wibowo, Department of Industrial Engineering, Faculty of Industrial Technology, University of Atma Jaya Yogyakarta, Yogyakarta, Indonesia

Y.D. Saputro, Department of Industrial Engineering, Faculty of Industrial Technology, University of Atma Jaya Yogyakarta, Yogyakarta, Indonesia

\begin{abstract}
Patients with diabetes often desperately need ankle foot orthotics (AFO) to perform daily activities. In Indonesia, experienced shoemakers employ manual procedures and follow the prescriptions given by a doctor or orthopaedic technician. This process remains traditional in that each pair of AFO is handmade, not precise, and is time consuming. This article describes the development of the design process and fabrication of a new AFO product for patients with diabetes based on a computer aided reverse engineering system (CARESystem). The reverse innovative design approach method discussed in this paper sought to achieve the best shoe last. The results also shows a functional test with highly satisfactory results. The shape of the shoe fit the standard AFO and the first patient experienced comfort for the 4-week long testing period. This article proves that the CARESystem technology successfully reduced the time for both the design and fabrication of the AFOs by $64 \%$.
\end{abstract}

\section{KEYWORDS}

Ankle Foot Orthotic, Caresystem, Orthopedic, Reverse Innovative Design

\section{INTRODUCTION}

Diabetes is a growing health problem around the world. WHO (World Health Organization) estimates that by 2030, more than 334 million people will suffer from diabetes (see Bernabeu et al., 2013; Davia et al., 2011, www.who.int/diabetes), while in 2009, diabetes affected 220 million people. Diabetes is a lifelong condition that seriously affects a person's quality of life. In recent years, the progress of medical treatments for curing diabetes has fortunately resulted in a considerable lengthening of life expectancy for many sick people. One of the 
most common complications is foot ulceration which, if left untreated, can lead to infection and ultimately to full or partial amputation (Janisse and Coleman, 2008). There are a number of footware-related factors that are considered to increase the likelihood of an individual developing an ulcer. These include elevated temperature/humidity within a shoe, increased in-shoe plantar pressure (pressure under the foot) (see Lavery et al., 2003, Amstrong, 1998) and increased shear movement between the foot and the shoe. Each of these factors will be dictated by different aspects of the design such as insole geometry (Bus et al., 2004; Anggoro et al., 2017a; Anggoro et al., 2018a), outsole profile/stiffness (van Schie et al., 2000; Brown et al., 2004), and shoe lasting (Cavanagh et al., 2002; Ameersing and Yan, 2009; Sambhav et al., 2011; Marco Mandolini et al., 2015).

The activities of standing, walking, and running are daily routines for most human beings, making insoles an important factor in general foot health and associated health issues. This fact has transformed the need for insoles from merely being an accessory into something functional. Most insole manufacturers are primarily concerned with cost-effectiveness, which leads to mass production. Unfortunately, such insoles might not always fit an individual's needs, as not everyone has the same gait or foot shape (Chung et al., 2011).

Researchers (Miguel et al., 2011; Luigi and Claudia, 2012) have described that the main problems for people with diabetes are due to the complications that such a sickness generates. One of the most relevant complications is called "diabetic foot". People with diabetes are at a higher risk for foot ulcers, a common side effect of the disease. It is estimated that $15 \%$ of diabetic patients are affected by this complication, but this number will probably grow due to lifestyle modifcations in many parts of the world, especially in emerging countries. The main cause of foot ulceration in an adult diabetic is thought to be the presence of abnormally high plantar pressures; neuropathy secondary to plantar fasciitis. These pressures may be present as a result of compromised foot function such as tendon disorders in the heel area of a foot and the diabetic condition, Charcot Anthropathy. The figures regarding swollen bones are shown in Figure 1 (see Anggoro et al., 2017b, Anggoro et al., 2018a, Anggoro et al., 2018b, and Bawono et al., 2017).

Over the last few decades, developments in the footwear industry have been characterized by the use of computer aided reverse engineering system (CARESystem) technology that produces strong and reliable products that range from the diagnostic stage of the patient's foot to the shoe-making stage. In this CARESystem application, there are three important steps that designers and the orthopedics industry need to heed as a result (Marco Mandolini et al., 2015):

Figure 1. Foot deformities of patients with diabetes (i.e. with swollen bone)

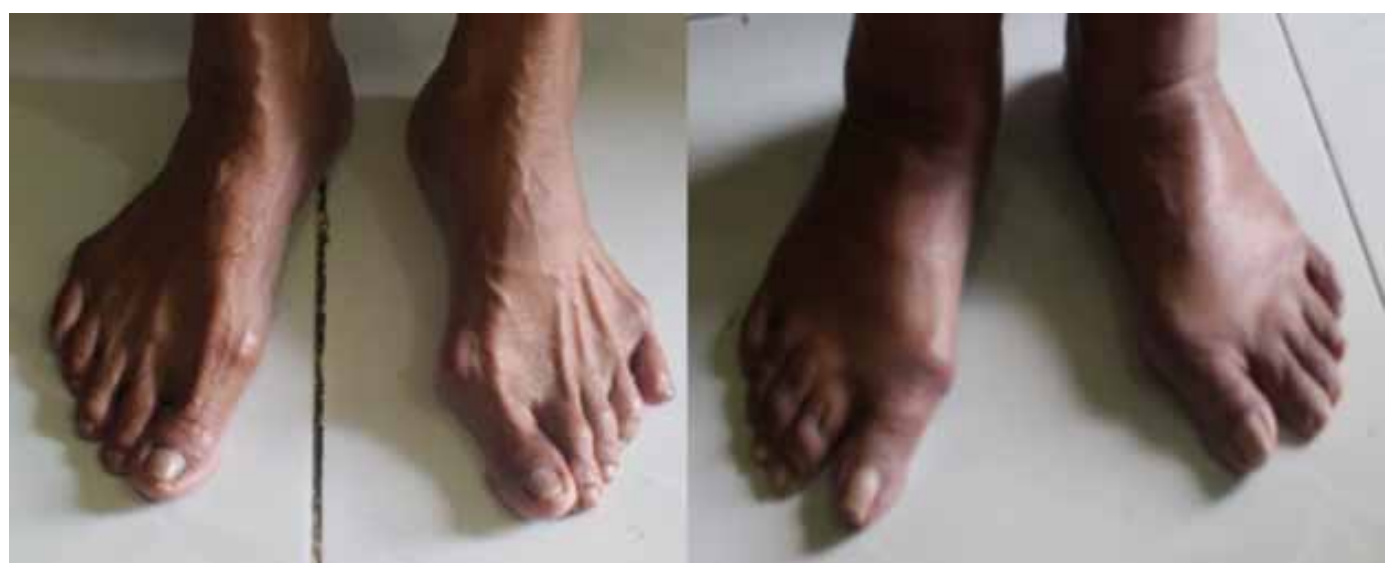


1. The diagnostic stage, where the scanning process of the patient's foot is done quickly and precisely with an increasingly sophisticated 3D scanner, provides various and reliable results in achieving the virtual geometry of the foot;

2. The design stage of footwear (insole, outsole, uppershoe, and lasting) specially designed with the help of specific, precise, and accurate computer aided design (CAD);

3. The production stage, where a CNC machine is used to produce the insole, outsole, and last. In this stage, to achieve the exact form of the insole, outsole, and last according to the design of the patient's foot, a good CNC machine is absolutely necessary.

In the world of orthopedics in Indonesia today, the work of crafting ankle foot orthosis (AFO) footwear products is still mostly done manually; handmade with a high dependence on a skillfully constructed shoe last and requires around 35-45 days for bespoke shoes and 5-7 days for insoles by (Davia et al., 2011), resulting in waste in both design time and manufacturing costs. In this specialized sector of AFOs, the changes in the foot contours in the foot deformities of patients are not the same and are also complex, so it can be a very unfavorable constraint for patients, orthopedic doctors, and the shoemakers, themselves. This has led to the need for improved methods of design and manufacturing of AFO products in Indonesia, specifically in Yogyakarta and Central Java. Nowadays, many foot pathologies are prevented or treated with custom made shoes and custom made insoles. A custom made shoe is realized from the base of a bespoke last. The last (shoe last) is a wooden or plastic shape, resembling a foot, which provides the final volumetric shape to the shoe (see Marco Mandolini et al., 2015). The last is important to provide an aesthetic value, as well as comfort and overall health to the foot. Many researchers have extensively discussed the significance of last design (Bernabéu et al., 2013; Miguel et al., 2011; Ameersing and Yan, 2009; Sambhav et al., 2011; Marco Mandolini et al., 2015; and Luximon, 2009). Rarely, however, has there been research that coherently integrates the detailed design and manufacturing processes of AFO products assisted by CARESystem technology from the patient's measurements as prescribed by doctors / orthopedists, scans of the patient's feet, insole and outsole design, and finally the lasting processes for shoes that fit the patient's feet. This research seeks to complete a detailed picture of the design and manufacturing process of AFO products with the CARESystem through the test phase in which the patients with diabetes assess their functionality.

To improve the quality of AFO products in accordance with the shape of the patient's foot, it is absolutely necessary to utilize CARESystem technology as has been reported by previous researchers. The basic principle of this technology is the application of the reverse innovative design (RID) method first introduced by Ye (2008) and successfully developed further by several researchers (Xia, 2014; Mandolini et al., 2015; Anggoro et al., 2017a; Anggoro et al., 2018c; and Anggoro et al., 2017d); specifically in using the CARESystem with the curve base surface modeling (CBS-modeling) method in both the design and production stages of custom orthotic insole shoes for patients with diabetes.

Various research on the integration of the orthotic design process and fabrication of orthotic shoes (AFO) (Capman et al., 2013; Denise and Erick, 2006; Foley et al., 1990; Octavian et al., 2006a; Octavian et al., 2011b; Telfer and Woodburn, 2010; McMahon and Browne, 1998) considered additive technology and subtractive manufacturing in the process, but it is still too general and not yet to the stage of fabrication and testing of AFO products with actual users.

This research will develop the application of CARESystem Technology that utilizes the integration of 3D scanning technology, Computer Aided Design technology (CAD), Computer Aided Manufacturing (CAM), and the production of customized orthotic shoe insoles (AFO) through subtractive manufacturing technology (CNC machine) to the test stage of usage by a patient.

Anggoro (Anggoro et al., 2017a; Anggoro et al., 2018b; Anggoro et al., 2018c; and Anggoro et al., 2017d) successfully utilized CARESystem technology in the design and production process of cutomized orthotic shoe insoles for patients with diabetes. In order to produce an insole, outsole, and shoe last designed in accordance with the shape of a patient's foot, the reverse innovative design (RID) model (Ye et al., 2008; and Xia, 2014) and Curve Base Surface 
Modeling (CBS-modeling) applications were introduced (Ye et al., 2008). However, these AFO products also received complaints from patients, similar to those previously heard, though not in terms of performance and comfort, but in terms of shape or the aesthetics of the shoes produced. According to the patients, the resulting model still looked rigid and conventional (for an orthotic shoe) so as to give an uninteresting impression (see Anggoro et al., 2018c). The initial AFO form is shown in Figure 2.

The main aim of the present study is to develop a beneficial, innovative method with the CARESystem to produce a new AFO for patients with diabetes. This AFO consists of the insole, outsole, and the orthotic shoes, themselves. The stages of this research start with scanning the patient's feet with HandySCANN 700TM to get the foot shots in .STL format. These files are then verified with VX Element to obtain a precise and fitting 3D mesh foot. PowerSHAPE 2016 software is used to convert the 3D mesh foot of the patient in .IGES format into a 3D CAD insole, outsole, and shoe last with the CBS-modeling method developed firstly by Ye (Ye et al., 2008). The results of the development of the latest design model of the insole, outsole, and shoe last will be optimized by manufacturing with CAM PowerMILL 2016. This optimization aims to obtain optimal cutting parameter conditions on the CNC machines. Two CNC machines were used in this research to obtain the three AFO products. The upper shoe section of the AFO is done by a home-based shoemaker based on a shoe last obtained with a CNC machine.

This paper also explains the design and production stages, in detail, of both the old and new AFO designs in accordance with the appearance of the model as desired by the patients. The RE and CBS-modeling methods will also be applied in this paper to build a new shoe last model according to the patient's desired shoe model.

Figure 2. Ankle Foot Orthosis for patients with diabetes mellitus: (a) Previous AFO product; (b) Previous shoe last models for both patients (Anggoro, et. al. 2018b)

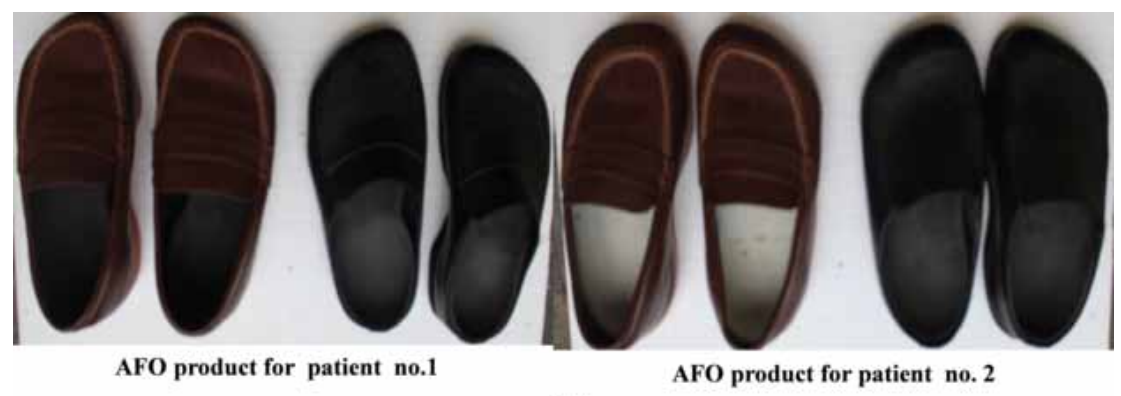

(a)

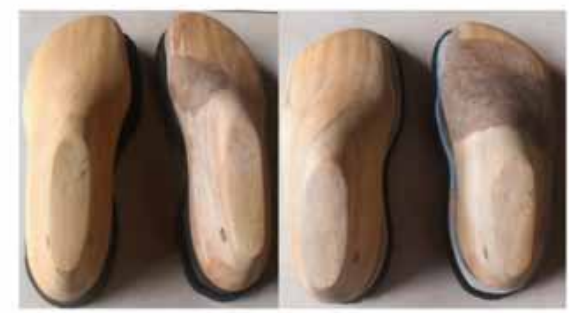

Shoe Last for patient no. 1 (left) and for patient no. 2 (right)

(b) 


\section{MATERIAL AND METHODS}

Consistent with previous research (Anggoro et al., 2018a; and Anggoro et al., 2017d), two patients with diabetes were selected as models to design AFO products according to the shoe form and the model desired by each patient. Initial research results (Anggoro et al., 2018c) obtained two pairs of AFO products as shown in Figure 2 (a). The dimensions and quality of the shape of these two AFO products completely fit and both patients were of the opinion that they were comfortable. The results of initial performance tests with both patients (Figure 1, Figure 2 (a) and Figure 5 (a) provide a convenience value of 3.8 to 3.9 on a mean scale 4 . This means that in terms of geometric quality, shape quality, and functionality, it actually appears that the initial AFO product was good and worked well, but in terms of the design of the model or its artistic quality, the AFOs were still considered by both patients to be lacking because the AFO was perceived as rigid and unattractive, especially the front of the shoe as shown in Figure 3.

The CARESystem is used in this paper to respond to the challenge of creating AFO forms as desired by both patients (Figure 3 (c). The 3D mesh foot results of both patients (as shown in Figure 5 (b) are 3D mesh files in the fixed.STL format that will be converted to the IGES format. This format will allow for changing the shape into a 3D CAD shoe last model using the CBS-modeling method contained in the software PowerSHAPE 2016. In order for a 3D CAD shoe last model to be processed on a 3 Axis CNC machine, an additional skeleton is required for each shoe end as shown in Figure 4.

PowerMILL2016 is used in this paper to generate reports on the tooling design process, parameter condition optimization, and the machining process simulation to see the movement of the cutter and

Figure 3. Topography of AFO shoes, (a) views of the tips of shoes, (b) views of the tips of Shoe Lasts, (c) standard shoes desired by both patients

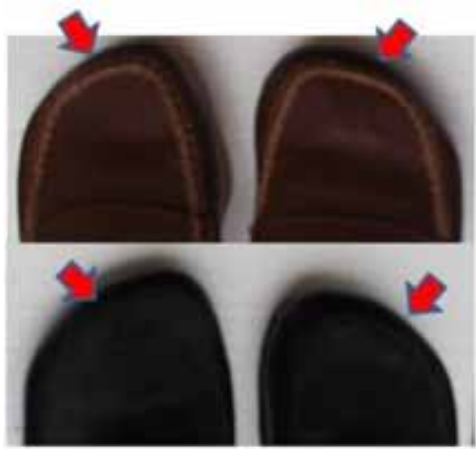

(a)

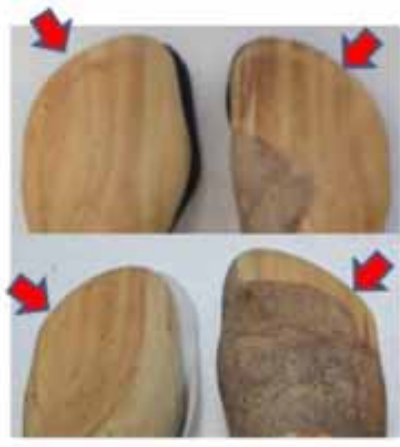

(b)

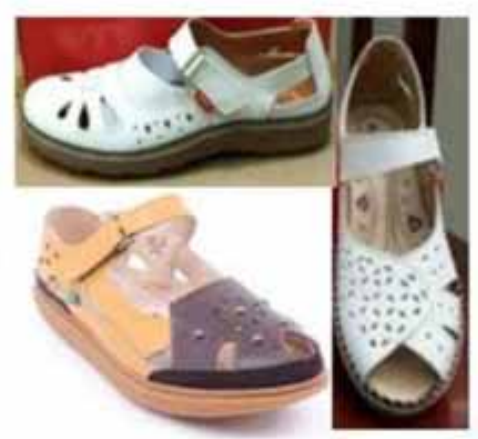

(c)

Figure 4. 3D CAD Shoe Last model for new AFO
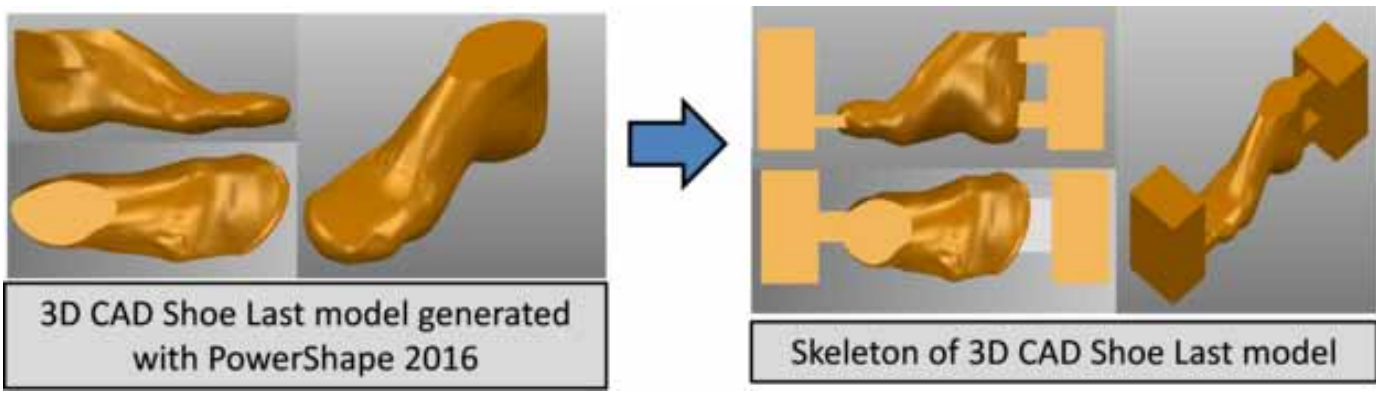

Skeleton of 3D CAD Shoe Last model 
the events that take place during the process, as well as to create NC Code with post processing in accordance with the CNC machine used (CNC YCM ev 1020 with 3 axes is used to manufacture the shoe last product.)

Ebalta type NECURON® $651(110 \times 330 \times 54 \mathrm{~mm})$ is designated as the shoe last material. This material was chosen because of its good machinability and it is suitable for either a product prototype or master pattern for the shoe mold; the chips produced are very light and keep the cutter sharp and durable. The characteristics of NECURON® 651 include a very fine structure, smooth and paintable surface, as well as excellent processing properties. This material provides good applications for master and copy models, cubing and data models, and general modeling. The characteristics of this material are shown in Table 1 (see http://necumer.com/images/pdf/en/NECURON_651_db.pdf and https://www.ebalta.de/fileadmin/user_upload/7._Downloads/eng/PUe.pdf)

The new AFO shoe for patients with diabetes is crafted by an expert shoemaker with more than 20 years of experience working in the general shoe industry making orthotic shoes by hand. The shoes will be made based on the latest shoe last shown in Figure 9. A flow chart methodology of the old shoe last model (conventional method) contrasting with the new shoe last model (CARESystem method) is presented in Figure 5.

\section{RESULT}

A shoe last is the base, or master mold, in shoe making. Without this important form, an expert shoemaker would find it difficult to produce shoes according to the customer's wishes. In this paper and based on Figure 5, we have developed and produced two types of shoe lasts, namely a manual shoe last (Figure 2.b) and a shoe last produced with the CARESystem (Figure 9). The CBS-modeling

Table 1. Characteristics of NECURON® 651

\begin{tabular}{|l|l|l|}
\hline \multicolumn{1}{|c|}{ Technical Data } & & \\
\hline Colour & brown & visual \\
\hline Coefficient of thermal expansion & approx. $55 \times 10^{-6} \mathrm{~K}^{-1}$ & DIN 53752-B \\
\hline Temperature resistance & approx. $65{ }^{\circ} \mathrm{C}$ & ISO 75 \\
\hline Shore D & approx. 70 & ISO 868 \\
\hline Compressive strength & approx. $25 \mathrm{~N} / \mathrm{mm}^{2}$ & DIN 53421 \\
\hline Flexural strength & approx. $27 \mathrm{~N} / \mathrm{mm}^{2}$ & ISO 178 \\
\hline Density & approx. $0.70 \mathrm{~g} / \mathrm{cm}^{3}$ & ISO 845 \\
\hline Abrasion resistance (at defined parameters) & approx. $-\mathrm{mm}{ }^{3}$ & DIN ISO 4649 \\
\hline Fire protection classification & B2 & \\
\hline Electrical current resistance & approx. $-\Omega$ x cm & IEC 93 \\
\hline Notched impact strength & approx. $-\mathrm{kJ} / \mathrm{m}^{2}$ & ISO $179-1$ \\
\hline Thermal conductivity & approx. $0.11 \mathrm{~W} / \mathrm{mk}$ & DIN 52612 \\
\hline Machining temperature & $20^{\circ} \mathrm{C}-25^{\circ} \mathrm{C}$ & \\
\hline Tools: & Metal-cutting tools & \\
\hline$\bullet$ Contains no halogens, plasticizer, or solvent & & \\
\hline$\bullet$ Manufactured fluorocarbohydrate-free & & \\
\hline$\bullet$ Physiologically harmless & & \\
\hline
\end{tabular}


Figure 5 (a) Conventional method of design process and production of the old AFO; (b) CARESystem method of design process and production of a new AFO
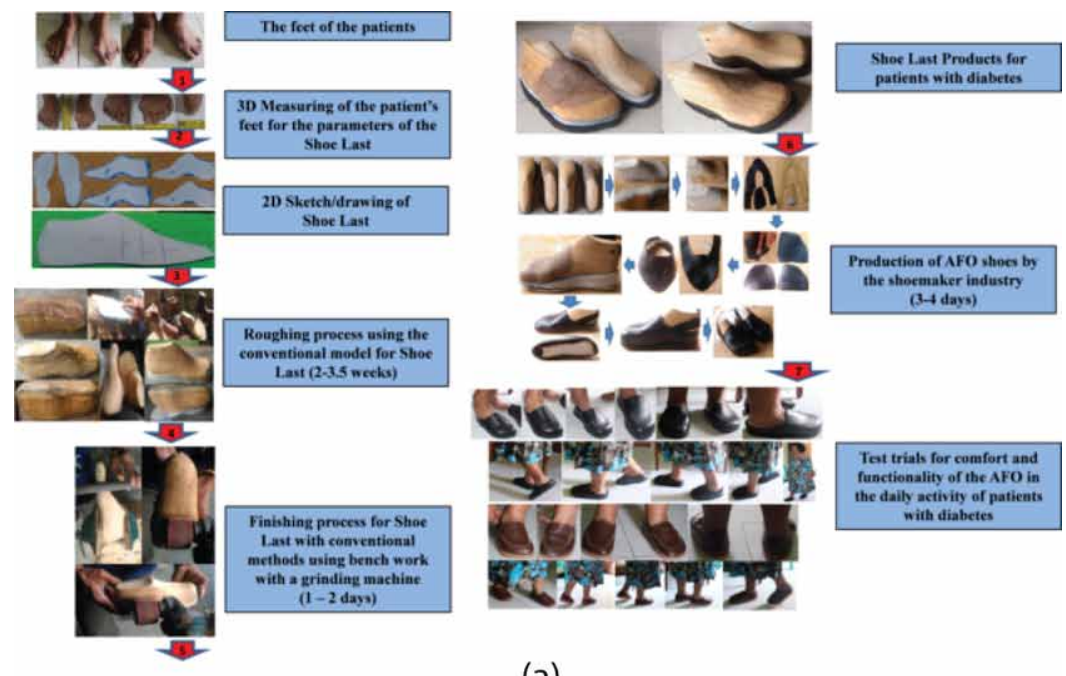

(a)
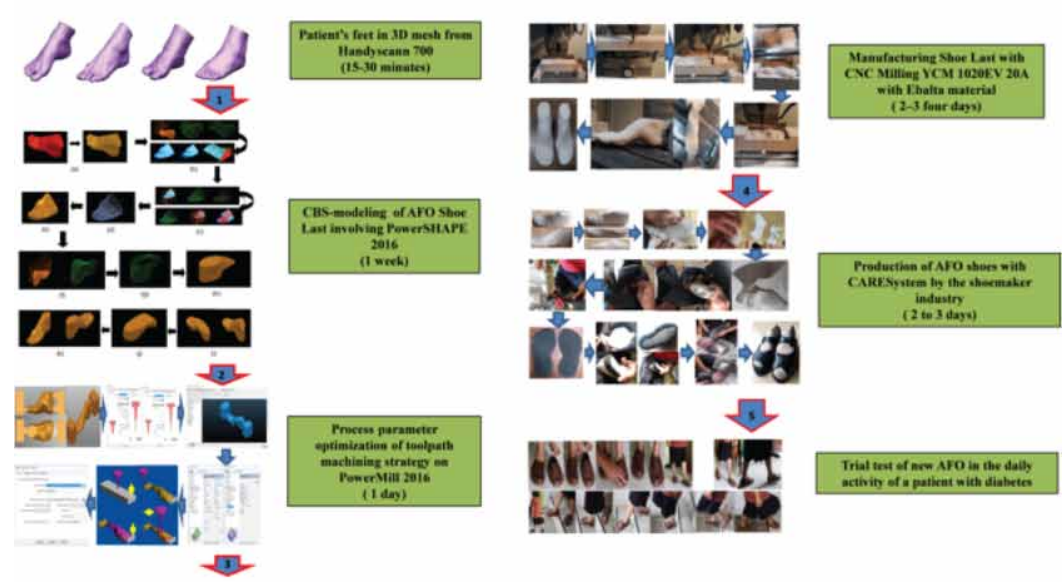

(b)

method, with the help of CAD PowerSHAPE 2016, was used in this research to create a new shoe last and the results are presented in Figure 6.

The result of CAM PowerMILL2016, along with the simulation process to the stage of creating an NC Code that will be used on the CNC machine for the work on the new shoe last, is presented in Figure 7.

The stages of processing a shoe last with the CARESystem in this paper were done using the CNC YCM 1020EV 20A presented in Figure 8.

The results of the shoe last machining process with the CNC YCM 1020 EV 20A machine are two custom pairs of shoe lasts for both diabetes mellitus patients and are presented in Figure 9.

Figure 9 is used as the basis for the process of making a new AFO for patients with diabetes in accordance with the standard AFO form in Figure 3 (c) and was successfully performed by an expert shoemaker in 2-3 days with the results as shown in Figure 10. 
Figure 6. CBS Shoe Last modeling with CARESystem involving Autodesk PowerSHAPE 2016: (a) convert surface model of the Shoe Last into a solid process, (b) create a good surface with an oblique curve on the front foot, editing the curve, surface modeling and smooth surface with cutting surface, (c) repoint curve surface to get a smooth surface of the front side of Shoe Last, (d) editing the wireframe, (e) 3D smooth surface model of the front side of Shoe Last, (f) oblique processing of foot, (g) editing curve construction, (h) surface of upper side of Shoe Last, i) upper side cutting of foot model with 3D view of the solid modeling, (j) round side cutting of solid modeling, (k) combined process of upper and front side of solid 3D shoe last model

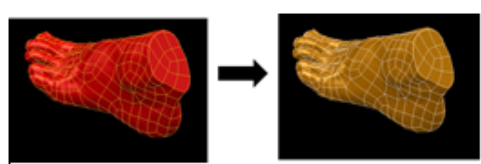

(a)

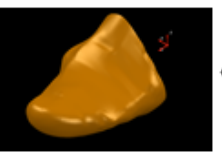

(e)
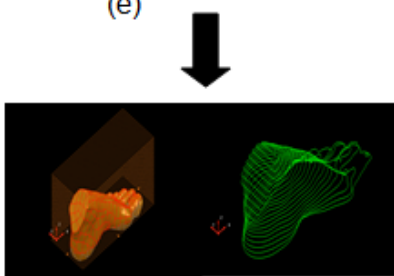

(f)

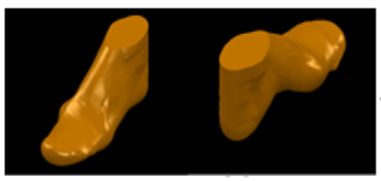

(k)

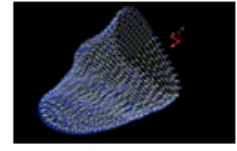

(d)

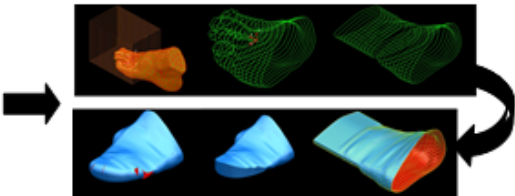

(b)

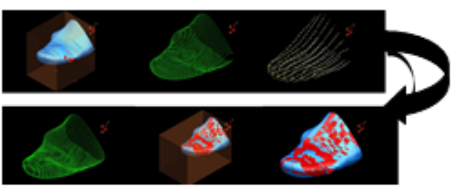

(c)

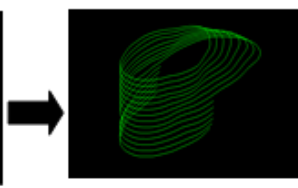

(g)

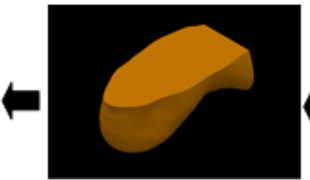

(j)

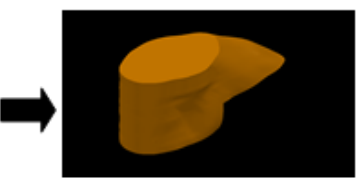

(h)

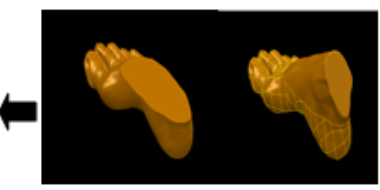

(i)

The assembled display between the shoe last and the patient's foot with the new AFO product can be seen in Figure 11.

\section{DISCUSSION}

The AFO shoe in Figure 2 (a) was successfully tested by Anggorod, et al (2018) by both patients for approximately 4 weeks with highly satisfactory results in both function and comfort. Both patients stated that the use of these shoes reduced the pain normally experienced during daily activities. The shoes proved comfortable when used by both female patients that are between the ages of 65-80 years. One important thing that the patients considered quite disturbing was that the shape of the shoes were not standard as are non-orthopedic shoes, in general. Figure 3 (a) and 3 (b) show that the tip of the shoe is not smooth, but follows the shape of the patient's foot so that when the shoe last result shown Figure 3 (b) was obtained, the shoemaker followed the form of the shoe last. The appearance of the shoes was not deemed by the patients to be appropriate models, although the qualitative aspects in geometry, functionality, and comfort were met very well. 
Figure 7. Stages of the simulation process for a Shoe Last in PowerMill 2016

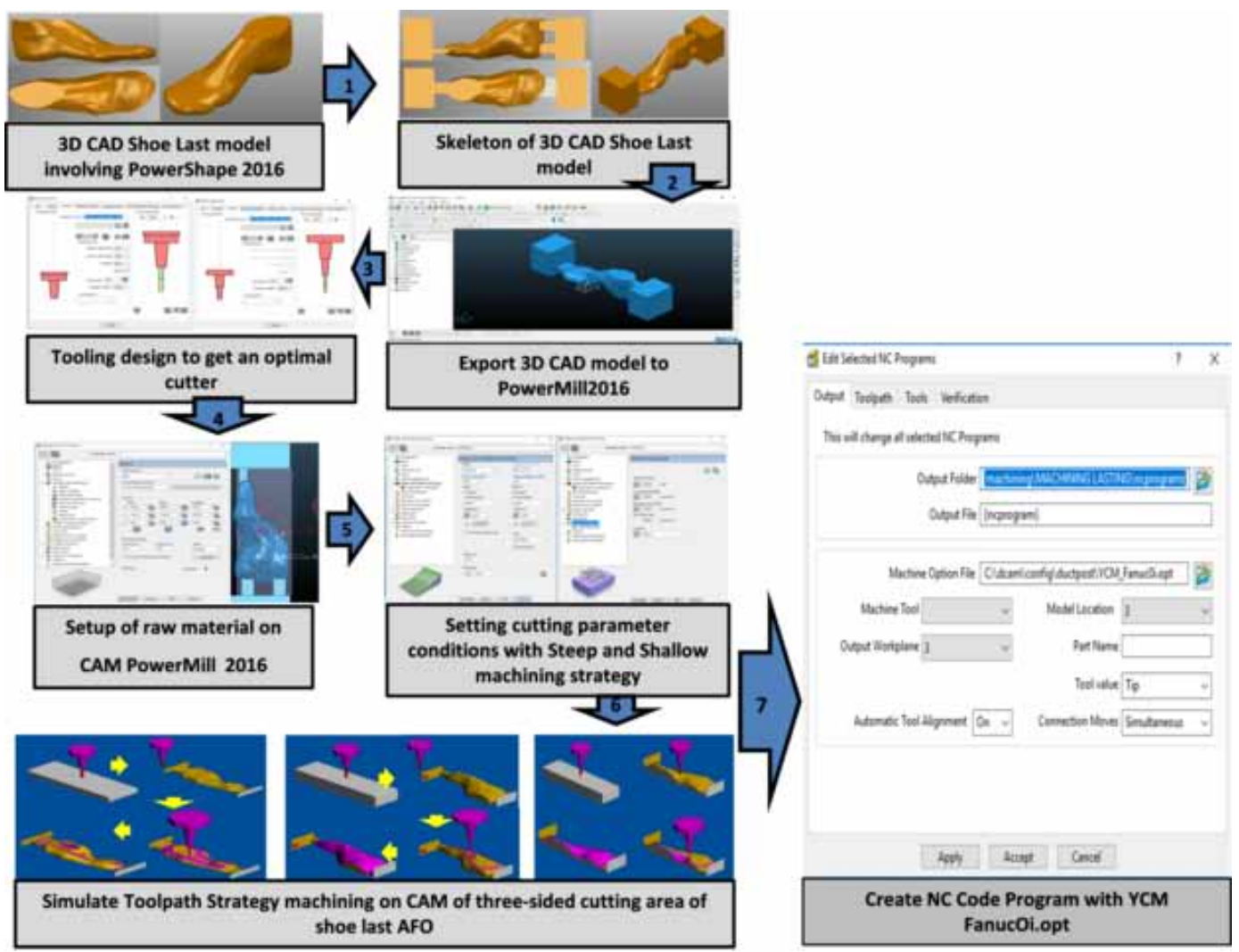

This paper discusses the improvement of shoe last design with the CARESystem method and shows an average time savings in the overall AFO production process as conducted by the researcher. Figure 5 explicitly describes all stages of the design process and production of AFO footwear traditionally / conventionally and with the CARESystem (as reported by Chung et al., 2011; Anggoro et al., 2017a, Anggoro et al., 2018b; Anggoro et al., 2018c, Anggoro et al., 2017d, Bawono et al., 2017, Marco Mandolini et al., 2015; and Sambhav et al., 2011). Researchers will also compare these two methods to see the aspects of comfort, precision, accuracy, and performed work time. The comparison of the measurment result of the average time to produce two pairs of AFO shoes for patients with diabetes is summarized in Table 2.

Based on Table 2, the experimentation demonstrated an average time savings of $64 \%$ for the overall AFO production process for patients with diabetes. This proves that the development of a new method with the CARESystem had a significant effect for AFO shoe designers to produce comfortable orthotic shoes extremely fast; accurately measured and with precise fit. This result shows an increase of about 24\% compared with research conducted by Mandolini et al. (2015). This result can actually be improved if CAD software is used to transform the 3D mesh foot into a 3D CAD shoe last model using special orthotic software such as Orthomodel, Last Designer software system, etc. The PowerSHAPE 2016 CAD software used in this research is able to produce some combinations of insole and shoe last designs as desired, but not as fast as using special orthopedic software. It takes about a day to produce the desired shoe last shape, but the quality of the image is so perfect that the image can be transferred to the manufacturing process on the $\mathrm{CNC}$. 
Figure 8. Manufacturing Stages of a shoe last on a CNC machine: (a) set-up NECURON $囚 651$ material, (b) setting 3 cartesian axes on the $A$ side of the shoe last, (c) roughing process on side A with EM Ø8mm, (d) output roughing process side $A$, (e) finish processing side $A$ with ball nose $\emptyset 6 \mathrm{~mm}$, (f) output finished side $A$, ( $g$ ) setting 3 cartesian axes on side $B$ of shoe last, (h) roughing process on side $B$ with EM $\varnothing 8 \mathrm{~mm}$, (i) output roughing side $B$, (j) finished processing side B with ball nosed $\varnothing 6 \mathrm{~mm}$, (k) output finished side $B$, (k) setting 3 cartesian axes on side $C$ of shoe last, (l) roughing process on side $C$ with EM Ø8 mm, (m) output roughing side $C$, ( $n$ ) finishing process on side $C$ with ball nosed $\varnothing 6 \mathrm{~mm},(0)$ finished output side $C$ of shoe last with skeleton, (p) shoe last of new AFO for patients with diabetes mellitus.

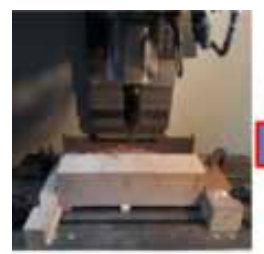

(a)

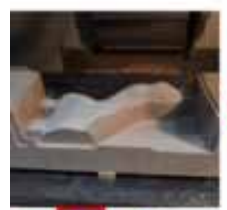

(j)

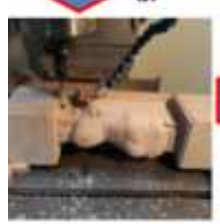

(k)

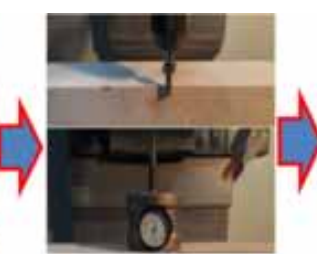

(b)

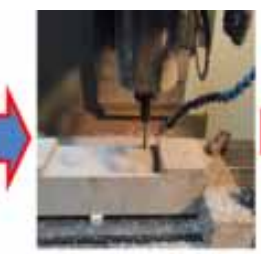

(c)

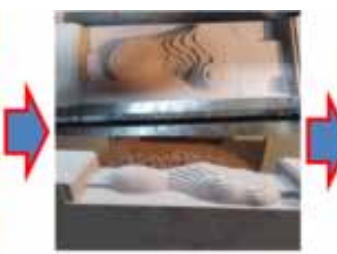

(d)

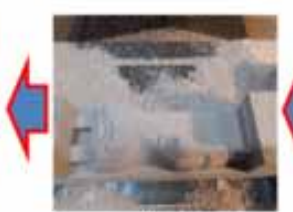

(i)

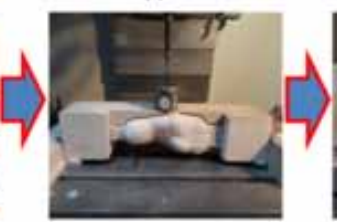

(I)

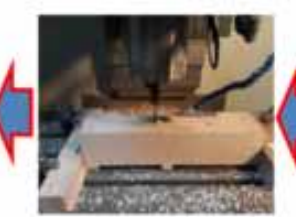

(h)

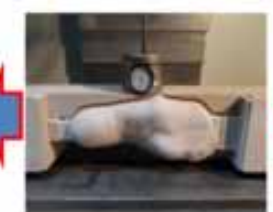

(g)

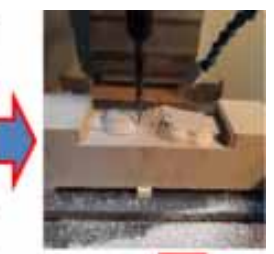

(e)

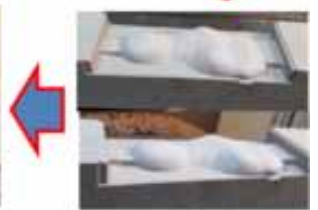

(f)

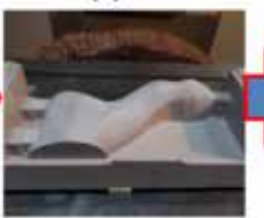

(m)

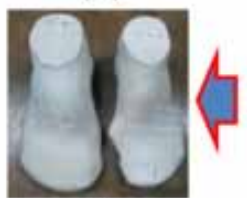

(q)

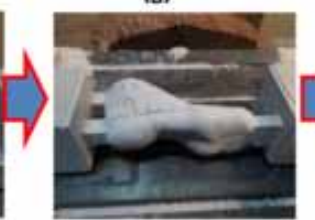

(n)

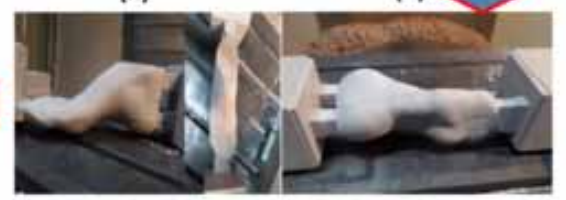

(p)

Figure 9. Shoe Last Product with CARESystem (a) patient no. 1, (b) patient no. 2

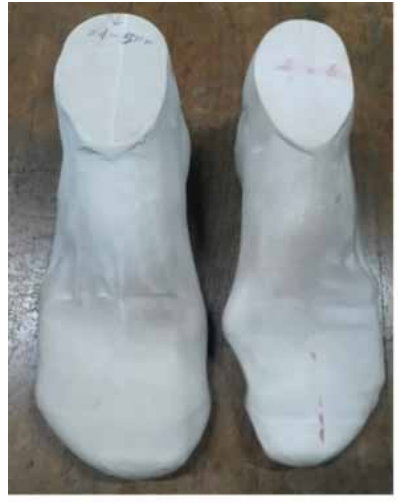

(a)

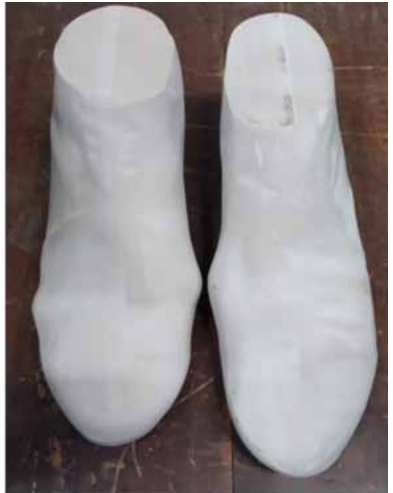

(b) 
Figure 10. A new AFO product for patients with diabetes mellitus: (a) patient no. 1, (b) patient no. 2

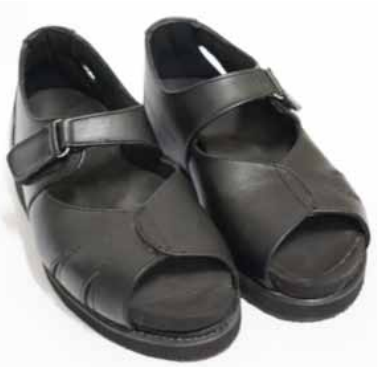

(a)

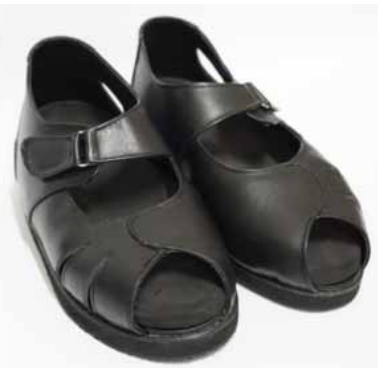

(b)

Figure 11. Tangible form of the Shoe Last of the patient's two feet in the new AFO shoes

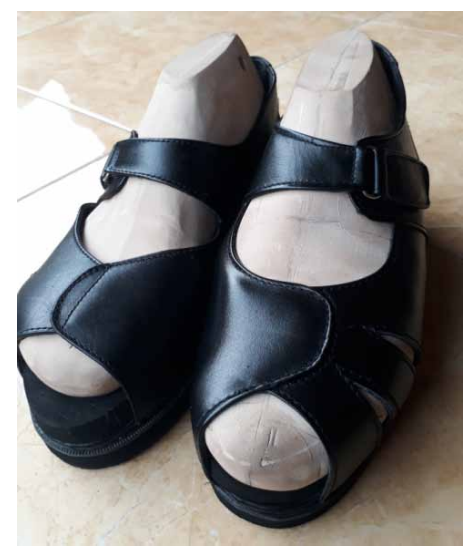

Table 2. Comparison between the time for data gathering and footwear design for traditional and CARESystem methods (average measured time for a pair of customized shoes)

\begin{tabular}{|l|l|l|l|}
\hline & $\begin{array}{c}\text { Traditional } \\
\text { Process (Minutes) } \\
\text { (Anggoro et. al, } \\
\text { 2018b) }\end{array}$ & $\begin{array}{c}\text { Caresystem } \\
\text { Process } \\
\text { (Minutes) }\end{array}$ & $\begin{array}{c}\text { Improvement } \\
\text { (Minutes) }\end{array}$ \\
\hline Acquisition of foot data & 3 & 3 & 0 \\
\hline Scanning physical model with Handyscann 700 & 0 & 10 & 10 \\
\hline Measurement of physical model to engineered shoe last & 60 & 0 & -60 \\
\hline CBS-shoe last modeling with CAD & 0 & 90 & 90 \\
\hline Manufacturing shoe last with conventional methods & 4800 & 0 & -4800 \\
\hline Process optimization with CAM PowerMill & 0 & 30 & 30 \\
\hline Manufacturing shoe last with CNC Machine & 0 & 1920 & 1920 \\
\hline Manually finishing shoe last & 960 & 60 & -900 \\
\hline Total Time & 5823 & 2113 & -3710 \\
\hline Overall time savings with the new AFO production process & & $\mathbf{6 4 \%}$ \\
\hline
\end{tabular}


The design and fabrication process for new AFO shoes for patients with diabetes begins with the shoe last design process based on the initial data of a 3D mesh foot. This data is the result of scanning both feet of the patient using HandySCANN 700TM as presented in Figure 5. (b). 3D mesh files are presented in the .STL file format which is then converted into an IGES file format for converting the date into a solid or a surface model. This is to support the CAD engineer in the process of image editing in PowerSHAPE2016. In the case of the shoe last design for an AFO product for patients with diabetes, the final process for the shoes of the patient is shown in Figure 11 and is divided into three stages: round side of foot, upper side of foot, and the bottom of the foot. This process is done to distinguish each section of each of the patient's feet that is not the same shape as the other surface contours of their foot, especially the bottom side. This needs to be done so that the final surface contours of the designed shoe last will completely match, be precise, and have the same surface contours as the lower legs.

Figure 12 is a 3D solid shoe last model as applied resulting from the CBS_Shoe_Last method for patients with diabetes (explanations for each stage can be seen in Figure 6.) This shoe last consists of five parts with names according to the image. To achieve the desired surface contours of the shoe last in accordance with the object (physical model, 3D mesh scanning, and 3D CAD foot and ankle model), a curve compiler was utilized. This curve, called a wireframe, consisted of a wireframe for the round side of the shoe and a wireframe for the upper shoe. The two wireframes are then changed into the three types of surface shape: round surface side of the shoe last, upper side surface of the shoe last, and the bottom side surface of the shoe last as shown in Figure 14, Figure 15, and Figure 16. In this paper, the bottom surface of the shoe last is obtained by taking the surface results of the patient's foot from the scan that is then converted into a surface model of the bottom of the patient's foot.

To obtain the rounded surface on the shoe last that corresponds to the standard shoe model as shown in Figure 3 (c) and according to the wishes of the two patients, it is necessary to change the shape of the rounded foot-side surface for the AFO for the patient as shown in Figure 13. This change is done by changing the original curved model based on the patient's foot into a new curve as shown in Figure 14, Figure 15, and Figure 16, as well as in accordance with the insole form as previously designed (Anggoro et al., 2017a; and Anggoro et al., 2018b) and well reported (Marco et al., 2015). The curve change process is performed by the engineer to form a rounded surface side for the patient's foot according to the face of the standard shoe shape. The results are presented in Figures 14, 15, and 16 .

Figure 12. 3D mesh CAD of patient with diabetes

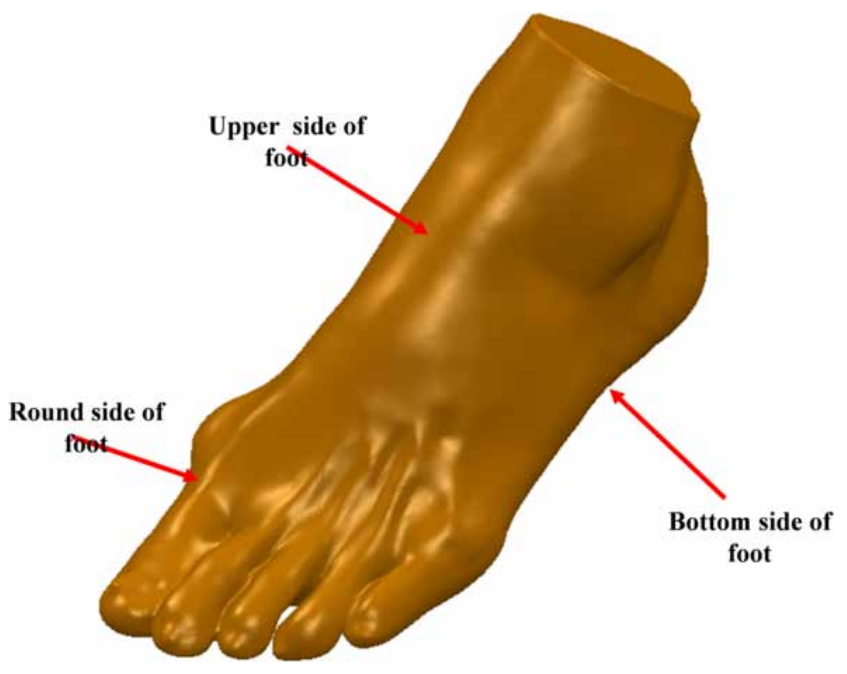


Figure 13. Divisions of shoe last design

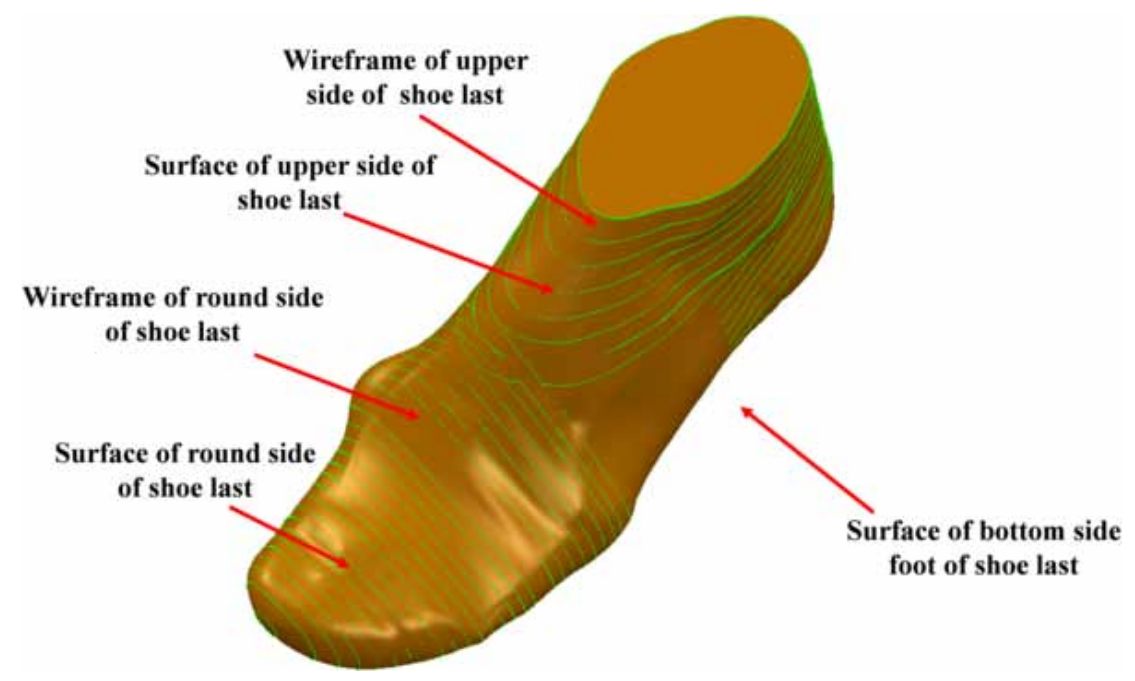

Figure 14. The front view of the original curve along with the newly designed curve that used CBS-Shoe last modeling involving PowerSHAPE 2016

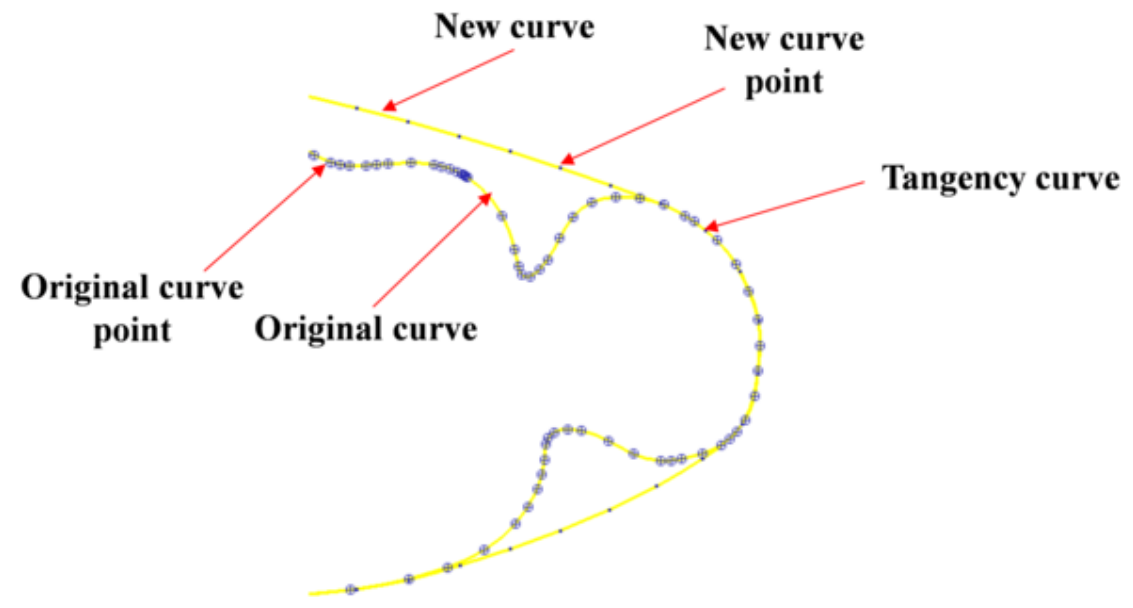

The beginning of the formation of the rounded side surface of the shoe last begins with the curve of the wireframe on the curve of the leg (Figure 13) with the oblique involved in PowerSHAPE2016 as the original curve of the foot. This original curve was developed again into a new smooth wireframe and has been adjusted to the surface contours of the shoe desired by the patients. The round-side portion of the shoe last is required by the patient in accordance with Figure 3(c). To get a smooth curve, the engineer needs to edit the curve with a cutting process on the original curve so that it will become a really smooth tangency curve (Figure 13) until obtaining the necessary smooth curve for making the surface of the shoe last.

In order to obtain a smooth, rounded side surface for the shoe based on the patient's request, the CAD shoe last engineer is required to perform a process to repoint the curves (Figure 14). This happens because the output of the curve creates a process with the oblique method and the edited curve often results in uneven positioning of each point curve, greatly affecting the smoothness quality 
Figure 15. The front view of the design process of the patient's foot (original curve of the patient's foot) changed into a real wireframe for creating the surface of the shoe last

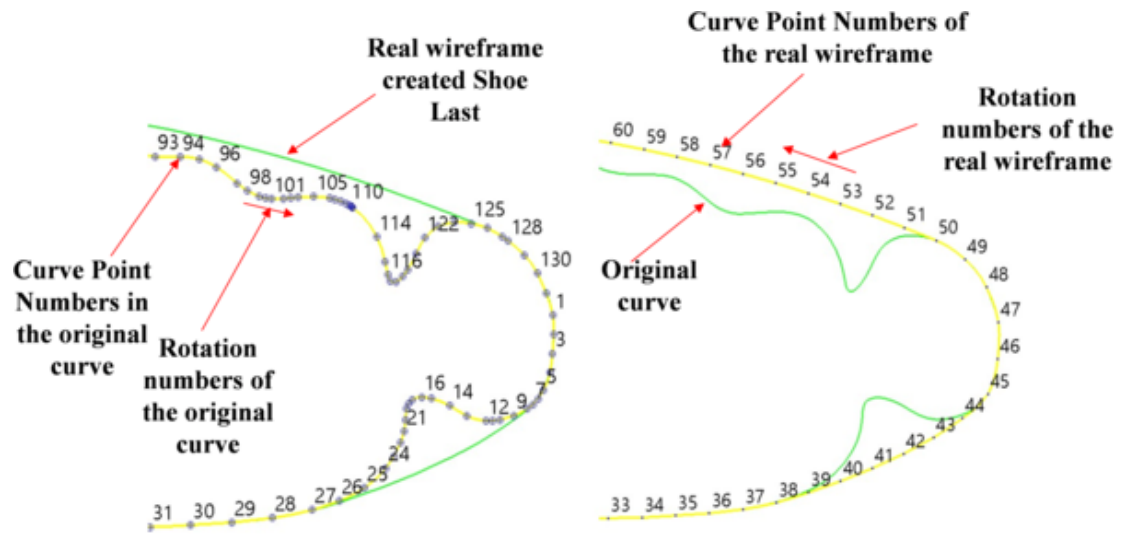

Figure 16. 2D front view of the smooth real curve creating a rounded side surface of the shoe last (red line)

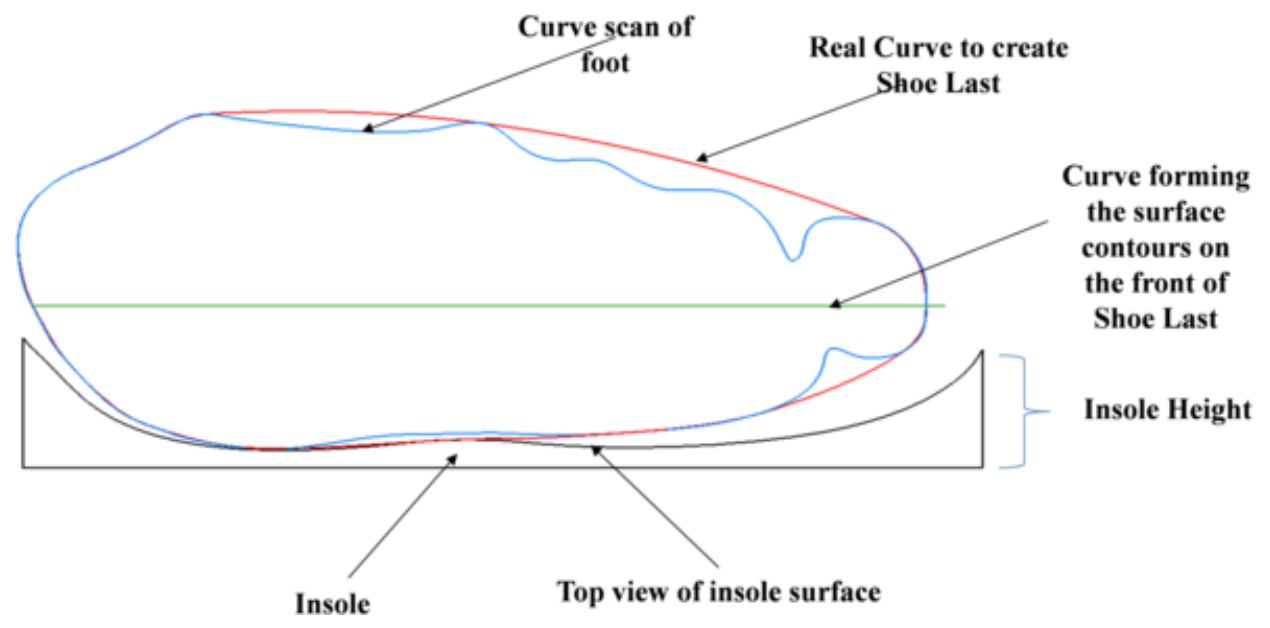

on the surface being built. This process is done by editing a number of curve points between the wireframes. This should result in the same number of curve points (Figure 15) and should also match the rotational direction of the curve point on the wireframe so that each new wireframe can perform the operation on the surfaces with automatic surfacing in PowerSHAPE2016; a smooth surface finally converted to CAM and processed on the CNC machines.

The wireframe for the 3D solid shoe last model in Figure 13, when presented in 2D drawing and juxtaposed with the insole shoe surface as produced by researchers (Anggoro et al., 2017a; Anggoro et al., 2018; Anggoro et al., 2018c; and Anggoro et al., 2017d), will show a clear comparison between the insole and real curve to create a new curve for the shoe last, the original curve of the foot from the scanning process, and the curve used to form the round side of the shoe last as presented in Figure 15. This figure shows the blue curve as the curve of the patient's foot from the scanning with Handyscann 700TM developed into a new model with curves forming the surface of the round side of the shoe last as shown in Figure 13. While the black curve (Figure 16) is a 2D wireframe insole which, when assembled with Figure 13, will be a 3D image including the shoe last with the orthotic shoe insole (Figure 17). 

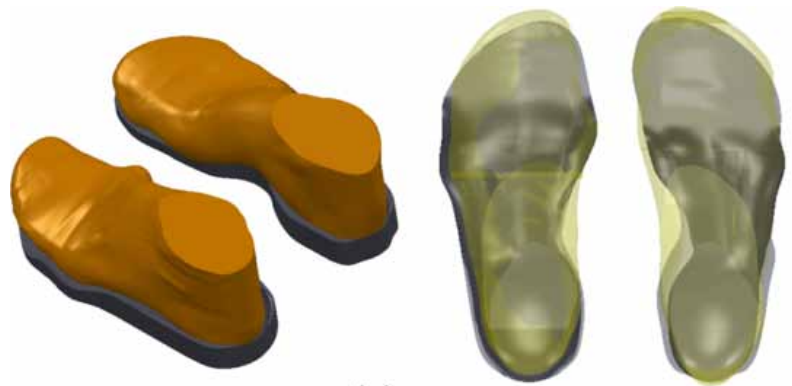

(a)
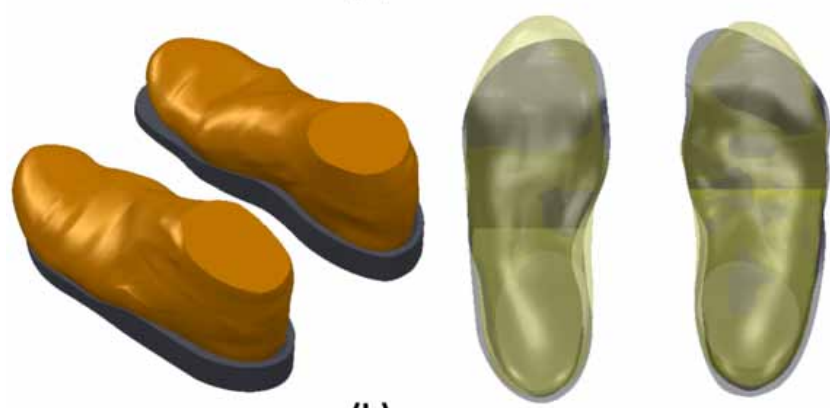

(b)

From Figure 16, it can be seen that the output of the CAD assembly process between the shoe last and the shoe insole creates a complete fit; so precise and accurate that it is ready for the next step in the shoe last product fabrication process with a CNC machine. In this paper, the new method of manufacturing a shoe last is not done manually as before by Anggoro et al. (2018). Why? Because the initial shoe last in Figure 2 (b) by the best shoemaker in both Central Java and the Special Region of Yogyakarta, Indonesia, took almost 3 weeks with imprecise results in the shape and dimensions of both the 3D CAD models and physical models. This caused the initial AFO footwear to be rigid and not fashionable; understandably inconsistent with the expectations of the patients.

The new shoe last crafted with the CARESystem method could be generated very well and the results are presented in Figure 5 (b), Figure 8, and Figure 9. The shape of the shoe last is in accordance with the 3D CAD model shown in Figure 4. To get two pairs, this recent shoe last will be created from both ends of the skeleton form based on the shape of the patient's foot to ease the manufacturing process on CNC machines. It takes approximately 32 hours of actual machining in a CNC machine to obtain two pairs of shoe lasts (Table 2 and Table 3).

Progress reports from PowerMILL2016 for each simulation performed, along with actual time recordings using a stopwatch, resulted in the average times presented in Table 3.

Based on Table 3(a) and Table 3(b), it is seen that in the development method of shoe last design and manufacturing, two machining strategies are used, namely offset area clearance for the roughing process and Steep \& Shallow Machining for the finishing process. Both strategies were chosen because they were able to provide excellent quality machining results (such as that done by Anggoro et al., 2018c; Anggoro et al., 2017d; Bawono et al., 2017e; Anggoro et al., 2016f). The cutting parameter condition in this paper follows these conditions:

1. Offset Clearance Area: $8 \mathrm{~mm}$ EM cutter used for the proccesses of both A and B sides on a spindle speed of $4500 \mathrm{rpm}$, feed rate of $1200 \mathrm{~mm} /$ minutes, a $1.2 \mathrm{~mm}$ thickness, and a $60 \mathrm{~mm}$ overhang cutter; 
Table 3a. PowerMILL2016 Shoe Lasting Project Program report for Patient No. 1

\begin{tabular}{|c|c|c|c|c|c|c|c|c|c|c|c|c|c|c|c|c|}
\hline \multicolumn{2}{|c|}{ PRODUK NAME } & \multirow{2}{*}{\multicolumn{2}{|c|}{ PART NANE }} & \multirow{2}{*}{\multicolumn{2}{|c|}{$\begin{array}{l}\text { CISTOMER } \\
\text { TING for PATIENT1 }\end{array}$}} & \multirow{3}{*}{$\begin{array}{c}\text { PROGRAM } \\
\text { Process }\end{array}$} & \multirow{3}{*}{$\begin{array}{l}\text { QUANTITY } \\
\text { STRATEGY }\end{array}$} & \multirow{2}{*}{\multicolumn{3}{|c|}{$\begin{array}{c}\text { MATERIAL } \\
\text { NECLRON } 651\end{array}$}} & \multirow{2}{*}{\multicolumn{2}{|c|}{$\begin{array}{c}\text { DATE } \\
2018-13-19\end{array}$}} & \multicolumn{4}{|c|}{$\begin{array}{l}\text { Data Cutting of Shoe Last on CAM PowerVill } \\
\text { and actual time on CIC Machine }\end{array}$} \\
\hline & & & & & & & & & & & & & \multicolumn{2}{|c|}{ Right Foot } & \multicolumn{2}{|c|}{ Left Foot } \\
\hline $\begin{array}{c}\text { PROGRAM } \\
\text { NAME }\end{array}$ & $\begin{array}{l}\text { TOOL } \\
\text { NAME }\end{array}$ & $\theta$ & TOOLTYPE & $\mathrm{OH}$ & HOLDER & & & n & $\mathrm{Vf}$ & Thick & $\begin{array}{l}\text { Tool } \\
\text { Offset }\end{array}$ & Tool $\mathrm{N}_{0}$ & $\begin{array}{l}\text { ESTCUT } \\
\text { IINE }\end{array}$ & $\begin{array}{l}\text { ACTUAL } \\
\text { CUTTIIVE }\end{array}$ & $\begin{array}{c}\text { ESTCUT } \\
\text { TIME }\end{array}$ & $\begin{array}{l}\text { ACTUAL } \\
\text { CUTTIME }\end{array}$ \\
\hline ROLG_A & EN6 & 8 & EndMill & 60 & D10 SCE34145801 1090 & A & Offset Area Clearance & 4500 & 1200 & 1.2 & $\mathrm{H}$ & 1 & 00.47 .03 & 0055503 & 1:01:11 & 01.15 .03 \\
\hline ROLG_ B & DN6 & 8 & EndVill & 60 & D10 SCE34145801 1090 & B & Offeet Area Clearance' & 4500 & 1200 & 1.2 & $\mathrm{H}$ & 1 & 00.45 .43 & 00.56 .43 & 1:04:09 & 01.13 .43 \\
\hline FINISH_A & $\mathrm{BN} 6$ & 6 & Ball Nosed & 60 & Bilz TSFV 0800-110/16 (Dia8) & A & Steepand Shallow & 6500 & 2500 & 0 & H & 1 & $0: 34: 52$ & 02.22 .52 & $0: 17: 33$ & 02.10 .52 \\
\hline FINISH B & $\mathrm{BN} 6$ & 6 & Ball Nosed & 60 & Bilz TSFV 0800-110/16 (Dia8) & B & SteepandShallow & 6500 & 2500 & 0 & H & 2 & 00.30 .40 & 02.10 .40 & $0: 17: 19$ & 02.10 .40 \\
\hline FINISH_C & $\mathrm{BN} 6$ & 6 & Ball Nosed & 60 & Bilz TSFV0800-110/16 (Dia8) & C & SteepandShallow & 6500 & 2500 & 0 & H & 2 & $0: 34: 13$ & 02.15 .13 & $0: 26: 39$ & $01,30.13$ \\
\hline \multicolumn{13}{|c|}{ TOTAL TINEMACHINING: } & 3.12 .31 & 8.40 .31 & 3.07 .11 & 8.20 .31 \\
\hline
\end{tabular}

Table 3b. PowerMILL2016 Shoe Lasting Project Program report for Patient No. 2

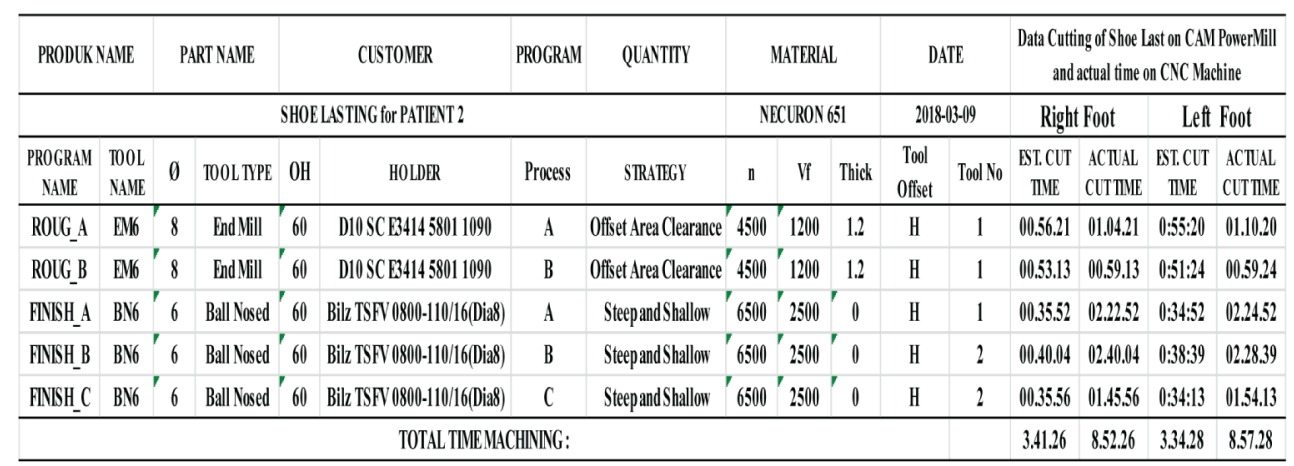

2. Steep and Shallow: Ball nosed $6 \mathrm{~mm}$ cutter used for work on the A, B, and C sides on a spindle speed of $6500 \mathrm{rpm}$, feed rate $2500 \mathrm{~mm} /$ minutes, a thickness of $0.0 \mathrm{~mm}$, and a cutter with a 60 mm overhang.

From Table 3 it can be seen that there is a difference in the shoe lasting time between the cutting estimate in PowerMILL 2016 and Actual time of 3.50 to 4.50 hours. This is due to two things:

1. Related to the machining time on a CNC machine, PowerMILL 2016 cannot simulate, with $100 \%$ accuracy, the time required for each process involving the movement of the cutter in feeding material and the movement when the cutter runs, but is "stuck" or otherwise unable to process/ cut the material; hung. This is because the $60 \mathrm{~mm}$ (Table 3) size of the overhang cutter length exceeds that of the patient's ankle height ranging from 40 to $50 \mathrm{~mm}$. An overhang this great will ultimately lead to vibrations in a large CNC machine, so it takes effort by the operator to reduce the vibration to avoid errors in the product, resulting in a longer machining time;

2. Based on Table 3 and Figure 8, there are three sides of the shoe last product. This causes the $\mathrm{CNC}$ operator to set the matieral and the cutter 3 times on the machine table before the roughing and finishing processes. This will impact the difference in actual time with the estimated time from PowerMILL. 
However, with the significant difference in time, it can be said that the development of a new shoe last manufacturing process with the CARESystem is ultimately able to provide time savings of about 3710 minutes (64\%) when compared to using traditional methods. The shoe last product in Figure 9 is an absolute match of the patient's foot, precise, and in accordance with the standard shoe form requested by the patient. Furthermore, with the help of shoemaker experts in the handcrafted shoe industry, these two pairs of shoe lasts are further processed into a new AFO for patients with diabetes as presented in Figure 10.

Testing the new AFO for the patients with diabetes has been done by the researchers with satisfactory results. The shoe shape is no longer rigid, but more smooth and in line with the expectations demanded by both patients.

\section{CONCLUSION}

The paper has presented a new method using $\mathrm{CAD}, \mathrm{CAM}$, and a $\mathrm{CNC}$ tool to design and manufacture shoe lasts for ankle foot orthosis, as well as the fabrication of a new AFO, for patients with diabetes.

Regarding clinical conditions in Indonesia, available commercial software or academic protoypes remain unused because AFOs continue to use conventional technology and are handmade. This paper succeeds in depicting the initial development process of AFO products (insole, outsole, shoe last, and orthotic shoes) with Handyscann 700TM 3D scanning, CAD PowerSHAPE2016, CAM PowerMILL2016, and a 3 axis CNC YCM 1020EV20A machine. In this paper, all existing infrastructure is fully integrated with other tools during the research process and this has enabled the transition from the traditional insole and orthotic shoe production processes to more innovative ones. The process stages used to model orthotic shoes have been described in detail by the researchers in order to demonstrate how the shoe last design and the geometry of the patient's foot significantly affected the insole.

Insole, outsole, and orthotic shoe designs with existing CAD software have been tried in an orthopedic laboratory in Jakarta and with both patients. Both of the technological process developments (traditional and CARESystem) have been conducted with the aim of responding to the complaints experienced by both diabetic patients over the years. After testing these two types of shoes for 2-4 weeks, both patients stated that they were very satisfied and felt comfortable performing daily activities.

The experimentation has demonstrated a $64 \%$ average increase in time savings in the overall process. Both patients acknowledged that in geometrical quality and comfort, there was no significant difference with traditional and innovative processes, but in terms of shoe aesthetics, both patients agreed that the innovative processes with the CARESystem resulted in orthotic shoes that really matched their expectations. It is possible to conclude that the proposed CAD tools and the related processes are feasible. Future research will be more focused on patients with different types of foot abnormalities, such as flat foot, high heel, diabetes with a history of amputation, and people with leg defects either from birth or through accident.

\section{ACKNOWLEDGMENT}

We would like to gratefully thank Mr. Rieky Lieberman as Managing Director of PT. Trimitra Wisesa Abadi, Jakarta, Inodnesia; Mr. Widagdo, Head of the Laboratory of Technology Manufacturing in the Department of Industrial Engineering, University of Atma Jaya, Yogyakarta, Indonesia; and the Tribology Laboratory of the Department of Mechanical Engineering of the University of Diponegoro in Semarang that already provided full infrastructure support in the form CAD, CAM, CAE, and $\mathrm{CNC}$ during the design and manufacturing process, in addition to the writing of this paper, os shoe last for an ankle foot orthosis for patients with diabetes. 


\section{REFERENCES}

Amstrong, D. G., Peters, E. J., Athanasiou, K. A., \& Lavery, L. A. (1998). Is there a critical level of plantar foot pressure to identify patients at risk for neuropathic foot ulceration? The Journal of Foot and Ankle Surgery, 37(4), 303-307. doi:10.1016/S1067-2516(98)80066-5 PMID:9710782

Anggoro, P.W., Bawono, B., Tauviqirrahman, M., Jamari, J., Bayuseno, A.P. \& Avellina, M.M. (2018b). Computer Aided Reverse Engineering System in the design and production of customized orthotic shoe insoles for patients with diabetes. Cogent Engineering. doi:<ALIGNMENT.qj></ALIGNMENT>10.1080/23311916.2018.1470916

Anggoro, P.W., Bawono, B., Tauviqirrahman, M., Jamari, J., Bayuseno, A.P. \& Wicaksono, A. (2018a). Reverse Innovative Design of Insole shoe orthotics for diabetic patients. Journal of Engineering and Applied Sciences, 13.

Anggoro, P. W., Bawono, B., Wibowo, J., Jamari, J., \& Bayuseno, A. P. (2017b). Optimization of Manufacturing Process Parameters for the Product of ISO-Diabetes Patients with High Risk Classes. Advanced Science Letters, 23(12), 11910-11917. doi:10.1166/asl.2017.10542

Anggoro, P. W., Bawono, B., Wijayanto, A., Jamari, J., \& Bayuseno, A. P. (2016). Parameter Optimatizion of strategies at CNC Milling Machines Rolland Modela MDX 40R CAM against surface roughness made insole shoe orthotic Eva Rubber Foam. International Journal of Mechatronic \& Mechanical Engineering., 06(4), 96-103.

Anggoro, P. W., Saputra, E., Tauviqirrahman, M., Jamari, J., \& Bayuseno, A. P. (2017a). A 3D dimensional finite element analysis of the insole shoe orthotic for foot deformities. International Journal of Applied Engineering Research., 12(15), 5254-5260.

Bawono, B., Anggoro, P. W., Anthony, A. A., Jamari, J., \& Bayuseno, A. P. (2017). Determining Optimal Toolpath Strategy in the Manufacture of Insole Shoe Orthotic Made from Eva Foam Rubber for Diabetes Patients. Advanced Science Letters, 23(12), 11902-11909. doi:10.1166/asl.2017.10541

Bernabéu, J. A., Germani, M., Mandolini, M., Mengoni, M., Nester, C., Preece, S., \& Raffaeli, R. (2013). CAD tools for designing shoe lasts for people with diabetes. Computer Aided Design, 45(6), 977-990. doi:10.1016/j.cad.2012.12.005

Brown, D., Wertsch, J. J., Harris, G. F., Klein, J., \& Janisse, D. (2004). Effect of rocker sholes on plantar pressures. Archives of Physical Medicine and Rehabilitation, 85, 81-86. doi:10.1016/S0003-9993(03)00374-5 PMID:14970973

Bus, S., Ulbrecht, J. S., \& Cavanagh, P. R. (2004). Pressure relief and load redistribution by custom-made insole in diabetic patients with neuropathy and foot deformity. Clinical Biomechanics (Bristol, Avon), 19(6), 629-638. doi:10.1016/j.clinbiomech.2004.02.010 PMID:15234488

Cavanagh, P. R., Boulton, A. J. M., Sheehan, P., Ulbercht, J. S., Caputo, G. M., \& Armstrong, D. G. (2002). Therapeutic footwear for people with diabetes. Journal of the American Medical Association, 288(10), 1231-1233. doi:10.1001/jama.288.10.1231 PMID:12215125

Chapman, J. D., Preece, S., Braunstein, B., Hohne, A., Nester, C. J., Brueggemann, P., \& Hutchins, S. (2013). Effect Rocker Shoe Design Features on Forefoot Plantar Pressure in People With and Without Diabetes. J Clinical Biomechanics, 28(6), 679-685. doi:10.1016/j.clinbiomech.2013.05.005 PMID:23731579

Denise, J. J., \& Erick, J. J. (2006). Pedorthic and Orthotic Management of the Diabetic foot. Foot and Ankle Clinics, 11(4), 717-734. doi:10.1016/j.fcl.2006.06.005 PMID:17097512

Foley, J., Van Dam, A., Feiner, S., \& Hughes, J. 1990. Computer Graphics, Principles and practice, reading, Addison-Wesley. Retrieved from .http://necumer.com/images/pdf/en/NECURON_651_db.pdf

Huang, C., Lee, M., \& Chang, C. (2011). Computer-Aided Design and Manufacturing of Customized Insoles. IEEE Computer Graphics and Applications, 31(March/April), 74-79. doi:10.1109/MCG.2011.19 PMID:24808031

Janisse, J. D., \& Coleman, W. (2008). Chapter 28: Pedorthic care of the diabetic foot:correlation with risk category. In Levin and O'Neal (Eds.), The Diabetic Foot (7th ed, pp. 529-546).

Lavery, L. A., Armstrong, D. G., Wunderlich, R. P., Tredwell, J., \& Boulton, A. J. (2003). Predictive value of foot pressure assessment as part of a population-based diabetes disease management program. Diabetes Care, 26(4), 1069-1073. doi:10.2337/diacare.26.4.1069 PMID:12663575

Lochner, S. J., \& Jan, P. (2012). Parametric Design of Custom Foot Orthotic Model. Computer-Aided Design and Applications, 9(1), 1-11. doi:10.3722/cadaps.2012.1-11 
Luigi, U. \& Claudia, G. (2012). The role of footwear in the prevention of diabetic foot problems. In The Diabetic Foot: Medical and Surgical Management, Contemporary Diabetes (pp. 519-529). Springer. doi:10.1007/978-1-61779-0_26

Luximon, A., \& Luximon, Y. (2009). Shoe-last design for better shoe fitting. Computers in Industry, 60(8), 621-628. doi:10.1016/j.compind.2009.05.015

Mandolini, M., Vitali, M. C., Macchione, A., Raffaeli, R., \& Germani, M. (2015). A CAD Tool to Design Bespoke Insoles for Severe Orthopaedic Treatments. Computer-Aided Design and Applications, 12(6), 700-709. doi:10.1080/16864360.2015.1033333

McMahon, C., \& Brown, J. (1998). CADCAM - principles, practice and manufacturing management. Harlow: Addison Wesley Longman.

Miguel, D., Michele, G., Marco, M., Maura, M., Enrique, M., \& Roberto, R. (2011). Shoes Customization Design Tools for the "Diabetic Foot". Computer-Aided Design and Applications, 8(5), 693-711. doi:10.3722/ cadaps.2011.693-711

Octaviana, C., Yavuz, S., \& Selman, H. (2006). Customized Foot Orthosis Manufactured with 3D Printers.

Octavianb, C. (2011). Mechanical Engineering Applications of Rapid Prototyping. In Int. Conf. on ManufacturingSystems (pp. 58-65).

Sambhav, K., Tandon, P., \& Dhande, S. G. (2011). Computer Aided Design and Development of Customized Shoe Last. Computer-Aided Design and Applications, 8(6), 819-826. doi:10.3722/cadaps.2011.819-826

Telfer, S., \& Woodburn, J. (2010). The use of 3D surface scanning for the measurement and assessment of the human foot. Journal of Foot and Ankle Research, 3(19), 1-9. doi:10.1186/1757-1146-3-19 PMID:20815914

van Schie, C., Ulbrecht, J. S., Becker, M. B., \& Cavanagh, P. R. (2000). Design criteria for rigid rocker shoes. Foot \& Ankle International, 21(10), 833-844. doi:10.1177/107110070002101007 PMID:11128014

World Health Organization. (n.d.). Diabetes. Retrieved from www.who.int/diabetes

Xia, Z. (2014). Application of Reverse Engineering based on Computer in Product Design. International Journal of Multimedia andUbiquitous Engineering, 9(5), 343-354.

Ye, X., Liu, H., Chen, L., Chen, Z., Pan, X., \& Zhang, S. (2008). Reverse innovative design - an integrated product design methodology. Computer Aided Design, 40(7), 812-827. doi:10.1016/j.cad.2007.07.006

P.W. Anggoro is a PhD candidate in the Mechanical Engineering Department of the University of Diponegoro, Indonesia. His research interest is product design based on Reverse Innovative Design Engineering with additive and subtractive manufacturing technology.

Mohammad Tauviqirrahman obtained a Doctoral degree from the Laboratory for Surface Technology and Tribology, University of Twente, the Netherlands.

Jamari received a Doctoral degree from the Laboratory for Surface Technology and Tribology, University of Twente, the Netherlands.

Athanasius P. Bayuseno is Professor in Material Science and Engineering and Head of the Graduate Doctoral Program in the Mechanical Engineering Department of Diponegoro University, Indonesia. His interest is dealing with ceramics, as well as materials science and engineering.

J. Wibowo received a B.Eng degree in Engineering from the University of Atma Jaya, Yogyakarta, Indonesia. His major research interest is CAM and CNC products.

Y.D. Saputro received a B.Eng degree in Engineering from the University of Atma Jaya, Yogyakarta, Indonesia. His major research interest is product design. 